\title{
Mediating role of supervisor on the association between work stress with physical and psychological symptoms among employees of Isfahan Steel Company in 2012
}

\author{
Kiani F, PhD, Khodabakhsh MR, PhD* \\ 1- PhD in Psychology, Young Researchers \& Elite Club, Shahrekord Branch, Islamic Azad University, Shahrekord, Iran. \\ 2- PhD in Psychology, Young Researchers \& Elite Club, Mashhad Branch, Islamic Azad University, Mashhad, Iran.
}

\begin{abstract}
Received: December 2013, Accepted: November 2013

Background: Nowadays job stress is one of the most important health problems that health and safety professionals are facing with. Much of previous studies have focused on interventions such as stress management and, they have ignored the role of psychosocial factors in occurrence of job stress. This study investigated the mediator role of supervisor support on the association between work stress and both physical and psychological symptoms, among Isfahan steel company employees in 2012.

Materials and Methods: The study questionnaire was completed by 189 employees of Isfahan Steel Company in 2012 who accepted to help with this descriptive study. The questionnaire consisted of items asking about work stress, physical and psychological symptoms as well as supervisor support.

Results: There were significant intercorrelations between the dependent and independent variables under research. Hierarchy regression analysis showed that supervisor support partially mediated the relationship between work stress and physical and psychological symptoms $(\mathrm{p}<0.05)$.

Conclusion: It was concluded that supervisor support is a protective shield against the effects of stress on psychological and physical health, among employees working in the steel company.
\end{abstract}

Keywords: Psychologic Stress, Musculoskeletal Diseases, Psychiatric Diagnosis, Cardiovascular Diseases

\section{Introduction}

The steel industry has one of the highest rates of fatal and non-fatal accidents/injuries every year. As a high risk industry, there is a need to investigate factors that affect the occurrence of these accidents in order to helping us to be able to protect workers [1]. Work stress is regarded as an important topic in the field of work health [2] because of its negative impacts on workers' health and safety [3]. It results from Long-term exposure to workplace psychosocial risks, characteristics of the work environment, work design, and organizational management which potentially cause psychological and social damages [4]. Work stress in occupational setting may also result in a physical or psychological reactions such as absenteeism, turnover, and job burnout [5], cardiovascular and coronary artery disease [6], gastrointestinal complaints, health problems, fatigue, injuries at work [7], sleep disturbance [8], disorder in social activities and quality of time spent with family [9], headaches, nausea, muscle pains [10], job dissatisfaction [11], affective disorder [12],

\footnotetext{
* Corresponding author: Mohammad Reza Khodabakhsh, Young Researchers \& Elite club, Mashhad Branch, Islamic Azad University, Mashhad, Iran.

Email: khodabakhsh@ut.ac.ir
} 
increased number of somatic symptoms such as neck and shoulder pain [13], type 2 diabetes in middle-aged women [14], susceptibility to disease [15], an increased risk of depression [16], and psychosomatic symptoms [17].

One of the primary obstacles against work stress and physical -psychological problems can be supervisor support [18]. Supervisors play a critical role in supporting the professional standards, expectations, and requirements that are conducive to a more supportive occupational settings as well as its critical role in the provision of workplace support [19]. Supervisor support is defined as workers' general views about the degree to which their supervisors value their contribution and care about their well-being [20]. Supervisor support provides employees with an important resource to manage stress [21].

The recent research showed supervisor support can buffer the hazardous effect of work stress on feelings of emotional exhaustion [22]. High levels of supervisor support reflecting care and concern for the health of employee leads to a reciprocal relationship in terms of increased safety behavior [23]. Supervisor support provides for employees an important resource to manage stress [21], enhance performance [24] and buffer the adverse effect of job demands on emotional exhaustion in situations with low decision authority [25].

Considering the stated material above, research about supervisor support can have many advantages for organizations and individuals due to increasing employees' safe behaviors and promoting safety level in workplace. However, less research has focused on psychosocial dimensions of workplace such as supervisor support. Also, the relationship between work stress and reporting of physical and psychological symptoms has not been studied adequately. Previous studies have mainly focused on particular industries [26], and no attempt has been made to describe the association between work stress and physical and psychological symptoms among Steel industry workers.

To summarize, the present study attempted to: 1) the examination of the likely relationship between work stress and physical and psychological symptoms; 2) the examination of the likely relationship between work stress and supervisor support; 3) the examination of the likely relationship between supervisor support and physical and psychological symptoms; 4) the specification of the mediator role of supervisor support in the relationship between work stress and physical and psychological symptoms.

\section{Materials and Methods}

This descriptive study was administrated between Jan and Feb 2012 in Esfahan Steel Company. Esfahan Steel Company (Zob Ahan-e Esfahan) opened in late 1960s, is based close to the cities of Fooladshahr and Zarrinshahr, Esfahan Province. Esfahan Steel Company (ESCO) is the first and largest manufacturer of constructional steel products in Iran $(\mathrm{No}=8300)$ [27]. In this study, in attention to the extent and distribution of the employees in the different parts of Esfahan Steel Company (Tohid Building, Navard part, blast furnace, steel making, coke, fire, railway, gas, oxygen plant, technical 
guidance etc.), Stratified random sampling was used to select the study sample. In stratified random sampling, the strata are formed based on members' shared attributes or characteristics. A random sample from each stratum is taken in a number proportional to the stratum's size when compared to the population. These subsets of the strata are then pooled to form a random sample. Then simple random sampling or systematic sampling was applied within each stratum. This often improves the representativeness of the sample by reducing sampling error. It can produce a weighted mean that has less variability than the arithmetic mean of a simple random sample of the population. The sample size was calculated using SPSS (version 15), Following the procedure recommended by Molavi (28). Given an, $\alpha$ level 0.05 and a power of 90 percent, the sample size required was estimated to be 180 subjects. Given the likelihood of failure to complete or return questionnaire, almost 200 employees were selected using stratified random sampling and questionnaires were distributed among them. Informed consent was obtained from each participant and the was study approved by the appropriately constituted ethics committees where the work was done.

The entry criterion for a person to this study was the employment at the company's sectors and the selection from among the members of his/her group randomly. The exclusion criterion of the individual was the delivery of incomplete questionnaire and lack of interest in participating in current research. Six members of the sample due to lack of interest in research topic, and 5 members due to incomplete questionnaires (in total 11 people) were excluded. Overall, 189 completed questionnaires were collected (95\% response rate). In order to control the confounding factors, questionnaires were completed by respondents in a quiet environment. Also, respondents were told that questions were listed in the questionnaire to evaluate only stress, psychological distress and physical symptoms that they have experienced due to their professional duties (not their family duties). Employees gave the written consent for their satisfaction on participating in this research and in order to avoid bias in answering questions, they were ensured that their responses would be confidential.

Validated instruments were used for data collection on work stress, supervisor support, physical symptoms and psychological distress. At first, all questionnaires were translated from English into Persian and independently back-translated into English by a second translator. The few discrepancies between the original English and the backtranslated version resulted in adjustment in the Persian translation based on direct discussion between the translators.

At the next step, psychometric characteristics of instruments were examined. Linguistic validation was performed by three experts of psychology department and five experts of safety and health departments. Thus, the questionnaires were piloted and finalized with an advisory group of workers to ensure that the scales items were comprehensible and appropriate to the context. Moreover, conceptual analysis confirmed the linguistic validity of all instrument. The questionnaires 
were distributed to workers with the help of union steward. Participants were assured of confidentiality and informed consent in written format was taken from each them.

\section{Scale of Supervisor Support for safety.}

Perceived supervisor support for safety with 15 items of Hayes, Perander, Smecko and Trask [29] was measured. Questions in the questionnaire are based on the amount and how employees interact with their supervisors. Two samples of the questions in this scale were: "My supervisor encourages me to express my ideas and opinions about safety at work", "My supervisor spends time showing me the safest way to do things at work". Respondents indicated the extent of agreement with each statement on a 5-point Likert-type scale $(1=$ strongly disagree; $5=$ strongly agree). The scores of participants were obtained by adding their responses to a 15-items questionnaire. Total score was grades of 15-75 that higher scores indicate that employees perceive work environment and their supervisors more supportive. Munteanu [30], calculated the internal reliability of this scale using Cronbach's alpha of 0/90. Evidence of reliability of this scale, as administered to Iranian relevant populations, in this research, by Alpha Coefficient is 0.80 and by Split-half is 0.78 The validity coefficients of questions and rating scales PSS are between 0.23 and 0.77 that all the validity coefficients are significant at $\mathrm{p}<0.0001$.

Physical symptoms scale. This scale is a 20 items questionnaire of Barling, Loughlin and Kelloway [31]. It is made based on the frequency of physical symptoms that employees have experienced them in their jobs during the past month. Scoring is based on a likert style of five degrees from 1 (never) to 5 (more than 5 times). Two samples of the questions in this scale were: "How frequently have you experienced headache or dizziness on the job?", "How frequently have you experienced persistent fatigue on the job?". Sum of the scores given to items is reported as the total score of physical symptoms for a worker. Prior studies surveying many industrials and organizations provide evidence for high internal reliability and validity of the scale (30). Internal consistencies (Cronbach's $\alpha$ ) in this study in Iran were 0.81 , which was excellent for this scale.

Psychological symptoms scale. This scale is a tool with 7 items of Barling et al. [31]. It is based on the frequency of psychological symptoms that employees have experienced them in their jobs during the past month. Scoring is based on a likert style of five degrees from 1 (never) to 5 (more than 5 times). Two samples of the questions in this scale were: " how frequently have you lost much sleep due to work related worries" and ", how frequently have you felt constantly under strain". Psychological distress scores are from 0 to 28 that high scores indicate more psychological distress experienced by the individual. Mantineau [30] reported the internal validity of this scale using Cronbach's alpha 0/83. Also, she showed that this scale had a good validity. Internal consistencies (Cronbach's $\alpha$ ) in this study in Iran were 0.79 , which was excellent for this scale.

Work stress. This scale was measured by Perceived Job Stress Scale (PSS) [32]. PSS is 
the most widely used psychological instrument for measuring the perceived job stress. It measures the degree to which situations in one's life are rated as stressful. The items asked for respondents how often they find their lives unpredictable, uncontrollable, and overloaded [33]. The scale also includes a number of direct questions about the current levels of experienced stress. All the items we used were modified to ensure that they were appropriate for the industrial context and included a number of direct questions about the current levels of experienced job stress. A sample item is "in the last month in workplace, how often have you been angry because of the things that were outside of your control.". The items of this questionnaire are grasped easily, and the response alternatives understand it simply. Further, the queries are of a public nature and thus are relatively free of content specific to any subpopulation group. The questions in the PSS ask about feelings and thoughts during the last month. In each case, respondents were asked how often they felt a certain way. Scoring was based on a Likert scale of four degrees from 0 (never) to 4 (very often). Mitchell, Crane and Kim [34] mentioned that this questionnaire has a high correlation with scales of "traumatic stress syndrome" and "quality of mental health". Also Demir and Orucu [35], in their study, mentioned the Cronbach's Alpha 0.84 and its correlation with the questionnaire "Public Health", 0.61. Evidence of reliability of this scale, as administered to Iranian relevant populations, in this research, by Alpha Coefficient is 0.82 and by Split-half is 0.77
The validity coefficients of questions and rating scales PSS are between 0.26 and 0.81 and all the validity coefficients are significant at $\mathrm{p}<0.0001$.

In order to test the mediating effect of supervisor support between work stress with physical and psychological symptoms multiple regression analyses were performed separately for each three-variable system in the model to assess the relations between work stress with physical and psychological symptoms via the hypothesized mediator which is supervisor support. According to Baron and Kenny, the following four conditions must be met to establish mediation: (a) The predictor variable must be related to the potential mediator, (b) the predictor must be related to the criterion variable and when the criterion variable is regressed on both the predictor and mediator variables, (c) the mediator must be related to the criterion variable, and (d) the previously significant relation between the predictor and criterion variables is attenuated [36]. All these requirements were examined and, in addition, the Sobel test [37] was used to test size and significance of the mediation effect. Data were analyzed using SPSS 15 software and $\mathrm{p}$ value less than 0.05 was considered statistically significant.

\section{Results}

The majority of participants were male, because the main occupational groups were at production line in this study. Ages ranged from 18 to 53; the mean age of the participants was $34 \mathrm{yr}(\mathrm{SD}=5.58 \mathrm{yrs})$ and average work experience was $12 \mathrm{yr}(\mathrm{SD}=3.2$ yrs) (Table1). 
Table 1: Demographic characteristics of the participants $(\mathrm{N}=189)$

\begin{tabular}{llcc}
\hline Variable & Groups & Frequency & $\begin{array}{c}\text { Frequency } \\
\text { Percentage [\%] }\end{array}$ \\
\hline Age & 18 to 29 years & 68 & $36 \%$ \\
& 30 to 41 years & 68 & $36 \%$ \\
& 42 to 53 years & 53 & $28 \%$ \\
\hline Sex & Male & 170 & $90 \%$ \\
& Woman & 19 & $10 \%$ \\
\hline Marital & Married & 113 & $60 \%$ \\
status & Single & 76 & $40 \%$ \\
\hline Education & Master degree & 22 & $12 \%$ \\
& University graduates & 45 & $24 \%$ \\
& High school graduates & 113 & $60 \%$ \\
& Primary school graduates and lower & 9 & $4 \%$ \\
\hline Work & 5 years and lower & 68 & $36 \%$ \\
experience & 6 to 15 years & 45 & $24 \%$ \\
& 16 to 25 years & 45 & $24 \%$ \\
& 26 years and higher & 31 & $16 \%$ \\
Shift & Shift & 120 & $64 \%$ \\
status & Not shift & 69 & $36 \%$ \\
\hline
\end{tabular}

Table 2 shows the descriptive statistics and intercorrelations of the study variables. Work stress was positively related to physical symptoms $\quad(\mathrm{r}=.34, \quad \mathrm{p}<.01), \quad$ and to psychological symptoms $(\mathrm{r}=.43, n s)$.
Supervisor support was negatively related to physical symptoms $(\mathrm{r}=-.33, \mathrm{p}<.01)$ and to psychological symptoms $(\mathrm{r}=-.23, \mathrm{p}<.05)$. Work stress was negatively related to supervisor support $(\mathrm{r}=-.25, \mathrm{p}<.05)$.

Table2: Mean, standard deviation and internal correlation between variables $(N=189)$

\begin{tabular}{lcccccc} 
& & & \multicolumn{5}{c}{ Correlations } \\
\cline { 6 - 7 } Measure & M & SD & $\mathbf{1}$ & $\mathbf{2}$ & $\mathbf{3}$ & $\mathbf{4}$ \\
\hline 1.Chronic work stress & $25 / 35$ & $4 / 94$ & 1 & & & \\
2.Physical symptoms & $16 / 93$ & $5 / 02$ & $0 / 34^{* *}$ & 1 & & \\
3.Psychological symptoms & $11 / 1$ & $4 / 33$ & $0 / 43^{* *}$ & $0 / 55^{* *}$ & 1 & \\
4.Supervisor support & $29 / 1$ & $2 / 51$ & $2 / 25^{*}$ & $0 / 33^{* *}$ & $0 / 23^{*}$ & 1 \\
$* \mathrm{p}<0 / 05, * * \mathrm{p}<0 / 01$ & & & & &
\end{tabular}

We used the approach proposed by Baron and Kenny [36] for testing mediation. In addition, in order to estimate significance and size of the indirect effect we employed the Sobel test (1982) [37]. Regression analyses were used to test the hypotheses about the mediating role of supervisor support. First, work stress regressed on supervisor support; supervisor support was found to significantly predict work stress ( $\beta=-.26 ; \quad p<0.05) \quad$ (second step). The regression analysis results are shown in Table $3 \& 4$. 
Table3: Results of mediation analysis for physical symptoms

\begin{tabular}{|c|c|c|c|c|c|}
\hline Baron and Kenny [1986] steps & B & SE & B & $\mathbf{t}$ & $\mathbf{P}$ \\
\hline & \multicolumn{4}{|c|}{ Direct and total effects } & \\
\hline $\begin{array}{l}\text { Step 1: physical symptoms regressed on work stress } \\
\text { [b path] }\end{array}$ & .21 & .099 & .23 & 2.06 & .042 \\
\hline $\begin{array}{l}\text { Step 2: work stress regressed on supervisor support } \\
\text { [a path] }\end{array}$ & -.118 & .049 & -.261 & -2.39 & .02 \\
\hline $\begin{array}{l}\text { Step 3: Physical symptoms regressed on work } \\
\text { stress, controlling for supervisor support [b' path] }\end{array}$ & .16 & .12 & .17 & -2.12 & .032 \\
\hline
\end{tabular}

\begin{tabular}{lcc}
\hline & Indirect effect and significant using distribution & \\
\hline & $\mathrm{Z}$ & $\mathrm{P}$ \\
Sobel & -2.22 & $0 / 03$ \\
\hline
\end{tabular}

Note. $N=189$.

A hierarchical regression analysis was conducted to examine the successive and independent contributions of work stress and supervisor support on physical and psychological symptoms (first and third steps). The effect of work stress to physical and psychological symptoms was reduced (although it was still significant) after supervisor support was entered in the equation at step 3 . This result was consistent with the presence of a partial mediation effect. The significance of the mediation effect was further confirmed by the significance of the Sobel test for physical symptoms $\quad(\mathrm{z}=-2.22, \quad \mathrm{p}<0.05)$ and for psychological symptoms $(\mathrm{z}=-2.4, \mathrm{p}<0.05)$.

Hence, the analysis provided support for the hypothesis of the mediating role of the supervisor support on the relation between work stress and physical and psychological symptoms.

Table 4: Results of mediation analysis for psychological symptoms

\begin{tabular}{|c|c|c|c|c|c|}
\hline Baron and Kenny [1986] steps & B & SE & $\mathbf{B}$ & $\mathbf{t}$ & $\mathbf{P}$ \\
\hline & \multicolumn{4}{|c|}{ Direct and total effects } & \\
\hline $\begin{array}{l}\text { Step 1: psychological symptoms regressed on work } \\
\text { stress [c path] }\end{array}$ & .35 & .079 & .45 & 4.41 & .000 \\
\hline $\begin{array}{l}\text { Step 2: work stress regressed on supervisor support } \\
\text { [a path] }\end{array}$ & -.118 & .049 & -.261 & -2.39 & .02 \\
\hline $\begin{array}{l}\text { Step 3: psychological symptoms regressed on work } \\
\text { stress, controlling for supervisor support [c' path] }\end{array}$ & .30 & .08 & .38 & -2.19 & .031 \\
\hline
\end{tabular}

stress, controlling for supervisor support [ $\mathrm{c}^{\prime}$ path]

\section{Indirect effect and significant using distribution}

\begin{tabular}{lcc}
\hline & $\mathrm{Z}$ & $\mathrm{P}$ \\
Sobel & 2.4 & $0 / 02$ \\
\hline
\end{tabular}

Note. $N=189$

\section{Discussion}

The results of the present study indicated that work stress has positive correlations with physical and psychological symptoms and a negative correlation with supervisor support. This is consistent with the findings of the previous studies [1, 38-43] and can be 
interpreted on the basis of the following possibilities.

Work stress is the condition in which some factors interfere with the worker to disrupt his or her physical or psychological health [44]. Previous research indicated work stress has positive correlation with physical and psychological symptoms such as Backache [45], Headache [46], Eye strain [47], Sleep disturbance [48], Fatigue [49], the decrease in appetite [50], gastrointestinal problems [51]. For example headache is pain experienced in the upper half and back of the head, in particular is associated with exposure to stressors such as scheduled hours, shift work, and lack of pre-work training [46]. Supervisor support consistently buffered the negative effect of work stress on the physical and psychological health among employee. Theoretical models of work stress also include a central role for support. The importance of supervisor support seems reasonable. Supervisor support is essential to motivating employee to excel and provision of support in workplace. Previous researches showed high levels of supervisor support were related to decreased work stress and a greater appreciation of the work [52].

The results of the present study indicated that supervisor support has a mediatory role in the relationship between work stress and physical and psychological symptoms. This is consistent with the findings of the previous studies [18, 52, 53-55] and can be interpreted on the basis of the following possibilities. Previous research indicated the availability of support from one's supervisor buffered the negative effects of work stress on health of employees. Employees with the perception of supervisor support realize that their health and safety for supervisory management is more important than the mere production; so they do not spend all their time for doing their jobs faster and do their work with more patience .On the other side, employees with the perception of work pressure have more job stress and want to do their work rapidly; therefore, at the time of working with organizational machinery and perhaps even at the time of their passing are involved in more accidents. The perception of employees about the company philosophy and its supervisor of production or safety, after the organization's policy towards safety, was the second important factor in predicting safety performance [56]. The theory of demandcontrol [DC], describes work stress as developing from the structural or organizational aspects of the work environment and not the individual characteristics [57]. A part of this theory as interaction between the job demands is put on the employee and the management to coordinate those demands [58]. Employees involved in positions with low control, high demands and low supervisor support, are in a higher danger of physical and psychological harm from work stress [59]. Mcclenahan, Giles and Mallett [60] concluded that high demands and low control and low supervisor support accounted for $26 \%, 6 \%$, and $8 \%$ of the variance in job satisfaction, psychological distress and burnout, respectively. Lack of supervisors' support and poor communication may act as stressors and therefore lead to the perception of work stress [61]. Supervisor support has effects which are beyond the perceived organizational support that is only associated with improved safety communications. Providing essential information and skills about mental health, including occupational stressors, have desired effects on the mental health of employees, at least in the short term [62]. Through providing information for subordinates or transferring attitudes or opinions about safety to them, often supervisors act as a driving force affecting 
workplace safety [63]. Perceived support of supervisor and co-workers from safety can reduce stress and the perception of stressors in workplace [64]. Supervisor support can mediate the impact of stressors on workers, in turn, cause them less likely to experience work stress [65]. Supervisor support provides employees with an important resource to manage stress and ultimately reduces the negative effect of work stress impact on physical and psychological symptoms. In order to minimize the occurrence of physical and psychological symptoms, it is important to provide supervisor support for employees [66]. Most organizations spend all their time in designing interventions for reducing stress. Although employees will learn ways to deal with stressors, when they enter the workplace, because of poor relations with supervisors and colleagues, get involved in the paradoxical situation. Learning from interventions becomes pale, and they fall in the same destructive cycle of conflicts. Studies have shown that supervisor support and the quality of communication between the supervisor and employees have a significant impact on learning transfer [67]. Therefore, in organizations supervisors and managers should be taught how to establish good relations with subordinates. Given the above contents, the mediator role of supervisor support in the relationship between work stress and physical and psychological symptoms include: Identifying important factors in the occurrence of work stress and the better design of human relations in the workplace which can mediate the effect of work stress on physical and psychological health of employees. The most effective procedure in which organizations can reduce work stress is modifying the sources of stress and creating a healthy workplace in occupational stress management. Increasing communication through greater opportunities for participation of employees in workplace and supervisor support training program on stress management might be effective ways for alleviating work stress, which would ultimately enhance workers' health. The present study needs to be replicated in different populations and needs more empirical support. Till then, the findings of the study should be interpreted with caution. Further, the cross-sectional design of the study and participants (i.e., a group of employees) exert some limitations on the generalization of the findings. Finally, the problems and limitations on the use of selfrepotting instruments should not be overlooked.

\section{Conclusions}

The results of the present study showed that supervisor support has a critical role in the relationship between job stress with psychological and physical health among employees.

\section{Acknowledgement}

The authors would like to acknowledge the generosity of employees who agreed to participate in this research.

Conflict of interest: Non declared

\section{References}

1. Kiani F, Samavatyan H, Pourabdian S, Jafari E. Predictive power of incidents reporting rate and its dimensions by job stress among workers' Isfahan Steel Company. Iran J Public Health 2011; 40(3):105-12. 
2. Leka S, Griffiths A, Cox T (2005). Work Organization \& Stress: Systematic problem approaches for employers, managers and trade union representative. Institute of Work, Health \& Organizations: Nottingham; P2533. (Protecting Workers' Health; Vol 3)

3. Conway PM, Campanini P, Sartori S, Dotti R, Costa G. Main and interactive effects of shift work, age and work stress on health in an Italian sample of healthcare workers. Appl Ergon 2008; 39(5): 630-9.

4. Cox T, Griffiths A, Barlow C, Randall R, Thompson L, Rial-Gonzalez E (2000). Organizational interventions for work stress: A Risk Management Approach. Institute of Work, Health and Organisations \& University of Nottingham Business School: Nottingham. P37-54.

5. Shanafelt TD. Enhancing meaning in work: a prescription for preventing physician burnout and promoting patient-centered care. JAMA 2009; 302(12):1338-40.

6. Shima S, Satoh E. Somatoform disorders in the workplace in Japan. Int Rev Psychiatry 2006; 18(1):35-40.

7. Muecke S. Effects of rotating night shifts: literature review. J Adv Nurs 2005; 50(4):433-9.

8. Harrma M. Work hours in relation to work stress, recovery and health. Scand J Work Environ Health 2006; 32(6):502-14.

9. Demerouti E, Geurts SA, Bakker AB, Euwema M. The impact of shift work on work-home conflict, job attitudes and health. Ergonomics 2004; 47(9):987-1002.

10. Li J, Yang W, Cho Sl. Gender differences in job strain, effort-reward imbalance, and health functioning among Chinese physicians. Soc Sci Med 2006; 62(5):106677.

11. Cavanaugh MA, Boswell WR, Roehling MV, Boudreau JW. An empirical examination of self-reported work stress among U.S. managers. J Appl Psychol 2000; 85(1):65-74.

12. Bromet EJ, Dew MA, Parkinson DK, Schulberg HC. Predictive effects of occupational and marital stress on the mental health of a male workforce. J Organ Behav 1988; 9(1):1-13.

13. Lundberg U, Dohns IE, Melin B, Sandsjo L, Palmerud G, Kadefors $\mathrm{R}$ et.al. Psychophysiological stress responses, muscle tension, and neck and shoulder pain among supermarket cashiers. J Occup Health Psychol 1999; 4(3):245-55.

14. Agardh EE, Ahlbom A, Andersson T, Efendic S, Grill V, Hallqvist J, et.al. Work stress and low sense of coherence is associated with Type 2 diabetes in middleaged Swedish women. Diabetes Care 2003; 26(3):719- 24

15. De Lange AH, Taris TW, Kompier MA, Houtman IL, Bongers PM. The very best of the millennium: Longitudinal research and the demand-control-(support) model. J Occup Health Psychol 2003; 8(4):282-305.

16. Tsutsumi A, Kayaba K, Theorell T, Siegrist J. Association between job stress and depression among Japanese employees threatened by job loss in a comparison between two complementary job-stress models. Scand J Work Environ Health 2001; 27(2):146- 53 .

17. Gershon RR, Lin S, Li X. Work stress in aging police officers. J Occup Environ Med 2002; 44(2):160-7.

18. Dickinson NS, Perry RE. Factors influencing the retention of specially educated public child welfare workers. J Health Soc Policy 2002; 15(3-4):89-103.

19. Mor Barak ME, Levin A, Nissly JA, Lane CJ. Why do they leave? Modeling child welfare workers' turnover intentions. Child Youth Serv Rev 2006; 28(5):548-77.

20. Eisenberger R, Stinglhamber F, Vandenberghe C, Sucharski IL, Rhoades L. Perceived supervisor support: Contributions to perceived organizational support and employee retention. J Appl Psychol 2002; 87(3):565-573.

21. Muse LA, Pichler S. A comparison of types of support for lower-skill workers: Evidence for the importance of family supportive supervisors. J Vocat Behav 2011; 79(3):65366.

22. Willemse BM, de Jonge J, Smit D, Depla MF, Pot AM. The moderating role of decision authority and coworker- and supervisor support on the impact of job demands in nursing homes: A cross-sectional study. Int J Nurs Stud 2012; 49(7):822-33.

23. Ayotte BJ, Margrett JA, Hicks-Patrick J. Physical activity in middle-aged and youngold adults: the roles of self-efficacy, barriers, outcome expectancies, self-regulatory behaviors and social support. J Health Psychol 2010; 15(2):173-85. 
24. Rhoades L, Eisenberger R. Perceived organizational support: a review of the literature. J Appl Psychol 2002; 87(4):698714.

25. Willemse BM, de Jonge J, Smit D, Depla MF, Pot AM. The moderating role of decision authority and coworker- and supervisor support on the impact of job demands in nursing homes: A cross-sectional study. Int J Nurs Stud 2012; 49(7):822-33.

26. Soori H, Rahimi M, Moheseni $H$. Occupational stress and work-related unintentional injuries among Iranian car manufacturing workers. East Mediterr Health J 2008; 14(3):697-703.

27. Esfahan steel Company. Profile of Esfahan Steel Company [Internet] 2012 Jan. Available from: http://www.esfahansteel.com/steel_form.php ?page $1=$ about $\&$ type $=1 \&$ pge $=$ profile

28. Molavi H (2007). SPSS 10-13-14 applied guidance in behavioral sciences. 2 ed. Isfahan: Poyesh Andishe Publication. P33-36. [Persian]

29. Hayes BE, Perander J, Smecko T, Trask J. Measuring perceptions of workplace safety: development and validation of the work safety scale. J Safety Res 1998; 29(3):14561.

30. Munteanu MR. Safety attitudes in the Ontario construction [Master's thesis]. Canada: University of Toronto; 2005.

31. Barling J, Loughlin C, Kelloway EK. Development and test of a model linking safety-specific transformational leadership and occupational safety. J Appl Psychol 2002; 87(3):488-96.

32. Cohen S, Kamarck T, Mermelstein R. A global measure of perceived stress. J Health Soc Behav 1983; 24(4):385-96.

33. Cohen S. Perceived stress scale. [Podcast on the internet]. Menlo Park: CA 94025 U.S.A; 2006 [January 10]. Available from: http://www.mindgarden.com/does/Perceived Stressscale.pdf

34. Mitchell AM, Crane PA, Kim Y. Perceived stress in survivors of suicide: Psychometric properties of the perceived stress scale. Res Nurs Health 2008; 31(6):576-85.

35. Orucu MC, Demir A. Psychometric evaluation of perceived stress scale for Turkish university students. Stress Health 2009; 25(1):103-9.
36. Baron RM, Kenny DA. The moderatormediator variable distinction in social psychological research: Conceptual, strategic, and statistical considerations. J Pers Soc Psychol 1986; 5(6):1173-82.

37. Preacher KJ, Hayes AF. SPSS and SAS procedures for estimating indirect effects in simple mediation models. Behav Res Methods Instrum Comput 2004; 36(4):71731.

38. Cropley M, Steptoe A. Social support, life events and physical symptoms: a prospective study of chronic and recent life stress in men and women. Psychol Health Med 2005; 10(4):317-25.

39. Wang JL, Lesage A, Schmitz N, Drapeau A. The relationship between work stress and mental disorders in men and women: findings from a population-based study. J Epidemiol Community Health 2008; 62(1):42-7.

40. Begen FM, Turner-Cobb JM. The need to belong and symptoms of acute physical health in early adolescence. J Health Psychol 2011; 17(6):907-16.

41. Demirtepe-Saygili D, Bozo O. Perceived social support as a moderator of the relationship between caregiver well-being indicator and psychological symptoms. J Health Psychol 2011; 16(7):1091-100.

42. Nixon AE, Mazzola JJ, Bauer J, Krueger JR, Spector PE. Can work make you sick? A meta-analysis of the relationships between job stressors and physical symptoms. Work \& Stress: An International Journal of Work, Health \& Organisations 2011; 25(1):1-22.

43. Lakkis NA, Osman MH, Musharrafieh UM, Issa GM. Psychological distress and job stressors among Lebanese workers: Experience from a private sector. Arch Environ Occup Health 2012; 67(3):133-44.

44. Lu L. The process of work stress: A dialogue between theory and research. Chinese Journal of Mental Health 1997; 10(1):19-51.

45. McLean SA, Williams DA, Stein PK, Harris RE, Lyden AK, Whalen G. Cerebrospinal fluid corticotropin-releasing factor concentration is associated with pain but not fatigue symptoms in patients with fibromyalgia. Neuropsychopharmacology 2006; 31(12):2776-82.

46. Bendtsen L. Central and peripheral sensitization in tension-type headache. Curr Pain Headache Rep 2003; 7(6):460-5. 
47. Gura ST. Yoga for stress reduction and injury prevention at work. Work 2002; 19(1):3-7.

48. Jansson M, Linton SJ. Psychosocial work stressors in the development and maintenance of insomnia: A prospective study. J Occup Health Psychol 2006; 11(3):241-8.

49. Smith AK, White PD, Aslakson E, VollmerConna U, Rajeevan MS. Polymorphisms in genes regulating the HPA axis associated with empirically delineated classes of unexplained chronic fatigue. Pharmacogenomics 2006; 7(3):387-94.

50. Kandiah J, Yake M, Willett H. Effects of stress on eating practices among adults. Fam Consum Sci Res J 2008; 37(1):27-38.

51. Ochi M, Tominaga K, Tanaka F, Tanigawa T, Shiba M, Watanabe T, et.al. Effect of chronic stress on gastric emptying and plasma ghrelin levels in rats. Life Sci 2008; 82(15-16):862-8.

52. AbuAlRub RF. Job stress, job performance, and social support among hospital nurses. J Nurs Scholarsh 2004; 36(1):73-8.

53. Choi B, Östergren PO, Canivet C, Moghadassi M, Lindeberg S, Karasek R, et.al. Synergistic interaction effect between job stress control and social support at work on general psychological distress. Int Arch Occup Environ Health 2011; 84(1):77-89.

54. Lapalme MÈ, Tremblay M, Simard G. The relationship between career plateauing, employee commitment and psychological distress: The role of organizational and supervisor support. The International Journal of Human Resource Management 2009; 20(5):1132-45.

55. Siu OL, Lu CQ, Spector PE. Direct and indirect relationship between social stressors and job performance in Greater China: The role of strain and social support. European Journal of Work and Organizational Psychology 2013; 22(5):520-31.

56. Isla Diaz R, Diaz Cabrera D. Safety climate and attitude as evaluation measures of organizational safety. Accid Anal Prev 1997; 29(5):643-50.

57. Theorell T, Karasek R (1990). Healthy work: Stress, productivity and the reconstruction of working life. New York: Basic Books. P20122 .
58. Vegchel NV, Jonge JD, Landsbergis PA. Occupational stress in (inter) action: The interplay between job demands and job resources. J Organ Behav 2005; 26(5):53560.

59. Dollard MF, Winefield HR, Winefield AH., Jonge JD. Psychosocial job strain and productivity in human service workers: A test of the demand-control-support model. J Occup Organ Psychol 2000; 73(4):501-10.

60. Mcclenahan CA, Giles ML, Mallett J. The importance of context specificity in work stress research: A test of the DemandControl-Support model in Academics. Work stress 2007; 21(1):85-95.

61. Steinhardt MA, Dolbier CL, Gottlieb NH, McCalister KT. The relationship between hardiness, supervisor support, group cohesion, and job stress as predictors of job satisfaction. Am J Health Promot 2003; 17(6):382-91.

62. Naghami M, Tsutsumi A, Tsuchiya M, Morimoto K. Job control and coworker support improves employee job performance. Ind Health 2010; 48(6):845-51.

63. Hofmann DA, \& Morgeson FP. Safetyrelated behavior as a social exchange: The role of perceived organizational support and leader-member exchange. Journal of Applied Psychology 1999; 84(2):286-96.

64. Babin BJ, Boles JS. The effects of perceived co-worker involvement and supervisor support on service provider role stress, performance and job satisfaction. Journal of Retailing 1996; 72(1):57-75.

65. Daalen GV, Willemsen TM, Sanders K. Reducing work-family conflict through different sources of social support. J Vocat Behav 2006; 69(3): 462-76.

66. Larsman P, Hanse JJ. The impact of decision latitude, psychological load and social support at work on the development of neck, shoulder and low back symptoms among female human service organization workers. Int J Ind Ergon 2009; 39(2):442-6.

67. Ismail A, Mohamed HB, Sulaiman AZ, Sabhi S. Supervisor's Role as an Antecedent of Training Transfer and Motivation to Learn in Training Programs. Economica 2010; 6(2):18-38. 